\title{
Problematic use of short message service (SMS) in medical students and its possible association with personality dimensions
}

Maryam Emadzadeh ${ }^{1}$, Foad Faroughi ${ }^{2}$, Mohammad Reza Fayyazi Bordbar ${ }^{3}$, Maliheh Dadgarmoghaddam ${ }^{4}$

${ }^{1}$ MD, Assistant Professor of Community Medicine, Clinical Research unit, Faculty of Medicine, Mashhad University of Medical Sciences, Mashhad, Iran

${ }^{2}$ MD, Faculty of Medicine, Mashhad University of Medical Sciences, Mashhad, Iran

${ }^{3}$ MD, Associate Professor of Psychiatry, Psychiatry and Behavioral Sciences Research Center, Mashhad University of Medical Sciences, Mashhad, Iran

${ }^{4}$ MD, Assistant Professor of Community Medicine, Department of Community and Family Medicine, Faculty of Medicine, Mashhad University of medical sciences, Mashhad, Iran

\section{Type of article: Original}

\begin{abstract}
Background: The use of short message service (SMS) is very popular among youths. Recent research has shown that it has some adverse consequences such as dependency.

Objective: The present research aimed to determine the frequency of SMS dependency and its association with the temperament and character of medical students.

Methods: A total of 293 medical students participated in this cross-sectional study in 2015 in Mashhad, Iran. The study group was divided into four groups according to their grade (using stratified sampling). Temperament and character inventory (TCI) and an SMS addiction test (SAT) were distributed between participants. SPSS software (version 11.5) was used for data analysis. Linear regression, Spearman's Rank-Order Correlation, Independentsamples t-test, ANOVA, Mann-Whitney U, and Kruskal Wallis were used for data analysis. P-value less than 0.05 was considered significant.

Result: The mean age of participants was $24.44 \pm 4.63$. Novelty seeking $(\mathrm{p}=0.003)$, cooperativeness $(\mathrm{p}<0.001)$, self-directedness $(p<0.001)$ and self-transcendence $(p=0.003)$ showed significant inverse correlation with total SAT score. There was significant difference between the mean of the total SAT in three state variables of novelty seeking $(p=0.02)$, cooperativeness $(p<0.001)$, self-directedness $(p<0.001)$ and self-transcendence $(p=0.02)$. The residents group had the highest mean SAT score. There was a significant difference in the total SAT scores according to the grade of the student $(\mathrm{p}<0.001)$. Moreover, we compared the participants' temperament and character with Iranian normative data (derived from a study conducted in 2005) and found that the mean score in each area differed significantly between the two datasets $(\mathrm{p} \leq 0.001)$.

Conclusion: Use of communication technologies is different according to temperament. Considering the key role of medical students, more attention needs to be paid to cellphone usage in this group.
\end{abstract}

Keywords: Personality assessment, Temperament, Character, Text messaging, Addictive behavior

\section{Abbreviations / Acronyms:}

ANOVA: Analysis Of Variance; NEO PI-R: Neuroticism-Extraversion-Openness Personality Inventory-Revised; SAT: SMS Addiction Test; SMS: Short Message Service; TCI: Temperament and Character Inventory

\section{Corresponding author:}

Assistant Professor Dr. Maliheh Dadgarmoghaddam, Department of Community Medicine and Public Health, Faculty of Medicine, Mashhad University of Medical Sciences, Mashhad, Iran. Tel: +98.9155084676, Fax: +98.5138002385, E-mail: dadgarmm@mums.ac.ir

Received: April 22, 2018, Accepted: September 28, 2018, Published: December 2019

iThenticate screening: March 19, 2019, English editing: March 27, 2019, Quality control: April 02, 2019

This article has been reviewed / commented by four experts

Funding: Vice Chancellery of Research, Mashhad University of Medical Sciences (Ref: 930914)

Ethics approval: Mashhad University of Medical Sciences (Ref: IR.MUMS.REC.1394.120)

(C) 2019 The Authors. This is an open access article under the terms of the Creative Commons Attribution-NonCommercialNoDerivs License, which permits use and distribution in any medium, provided the original work is properly cited, the use is non-commercial and no modifications or adaptations are made. 


\section{Introduction}

Ease of communication and ready availability of information characterize society today. In recent years, mobile phones have revolutionized communication. Today, communication via cellular technology (mobiles phones) is an integral part of life in many developed countries, with many people feeling they could not live without their mobile phone $(1,2)$. Research has shown that non-access to mobile phones can lead to anxiety, sensitiveness, sleep disorders and even physical ailments in some people (3-5). The use of text messages or short message service (SMS) is very popular among the youth (6). SMS was first introduced in Europe in the early 1990s, and it was introduced in Iran in 2002 (3). Lower cost, ease of communication with others and having more time to respond are the benefits of this service $(7,8)$. Despite the benefits of SMS, it has had some adverse consequences. For instance, it has resulted in a dramatic change in the way people communicate with each other, with some people preferring to communicate through SMS (or email), even if there is adequate time and facilities to meet and communicate (9). This kind of communication can lead to misunderstanding your addressee, because you do not have face to face communication or speak with each other. Messages are judged by the text or a sticker displayed on the screen.

SMS, which was introduced in Iran about 15 years ago, is one of the most widely used data applications today (3, $10)$. With increasing numbers of mobile phone users, a new problem has emerged: SMS addiction. Many people today are entirely dependent on mobile phones and consider them a central part of their lives (1). In 2012, a new word, 'phubbing', appeared in the media around the world. Phubbing refers to constantly checking a personal mobile phone while in company rather than engaging in conversation with the other individuals. It also refers to avoidance of interpersonal communication. The term is an amalgam of the words phone and snubbing, which refers to the habit of snubbing someone in favour of a mobile phone $(1,11)$. In two surveys conducted in the U.S. in 2015 , $46.3 \%$ of participants said their partners had phubbed them (12). Phubbing is widespread today, due to the availability of smartphones, with computer functionality and Internet access. Sending or receiving text messages while in company can be considered phubbing too.

The high prevalence of mobile phone and SMS usage among teens and young adults in recent years has given rise to concerns about dependence on SMSs in this population (13). Regardless of its advantages and disadvantages (low cost communication with others on the one hand; and inability of effective communication on the other hand), over use of SMS has other specific effects on the youth and students (14). Some studies have shown that SMS dependency (i.e. an addiction to SMS) is very common among university students and that it has caused problems such as poor academic performance or mental health issues, which have disrupted students' lives $(15,16)$. Studies showed that although cell phone use is prohibited in the classroom, some students reportedly continue to bring them into the classroom and use them. This behaviour has a negative effect on schoolwork and academic performance (5, 14, 17). According to one study, the psychological dependency on SMSs may be associated with personality, character and temperament (18).

The relationship between the use of SMSs and personality traits has never been a focus of research in Iran. There has also been no research on SMS dependency among medical students at various levels in their careers. As we know, by changing educational level, students deal with a new environment and different people, and this may lead to various reactions. Although medical students are a role model for other students in Iran and they are a special group with an extensive educational course, there are few studies describing the personality traits of this group and their usage of different media. Knowing how to use specific media according to personality traits may help public health decision makers in prevention from misuse of new communication tools and the substitution of them with guided methods. Considering the importance of this issue, the aim of the present study was to evaluate the frequency of SMS dependency and its association with the temperament and character of medical students at different stages of their career in the Medical Faculty of Mashhad University of Medical Sciences.

\section{Material and Methods}

\subsection{Research design and participants}

This was a cross-sectional study conducted in Mashhad, the second most populous city in Iran. Two hundred and ninety-three medical students from Mashhad University of Medical Sciences participated in this study in 2015. The study group was divided into four groups according to their grade: basic sciences (first and second-year medical students), externship, internship and residency. The method of sampling was stratified random sampling. The number of students in each level was identified and then we selected them by a computerized system of random numbers. The only inclusion criterion was being a medical student (in different grades). Non-native students were excluded from the study. 


\subsection{Measures and instrument}

A trained interviewer collected demographic data from the participants using a checklist and questionnaires. The checklist includes questions about age, gender, marital status, smoking behavior, etc. The question on smoking behavior was asked thus: "Have you ever smoked?". Two questionnaires including the temperament and character inventory (TCI) and SMS addiction test (SAT) were also distributed between participants. After the distribution of the questionnaires, the interviewer explained how to complete them. The data collection took approximately nine months. A shortened (125-item) version of the TCI, designed by Cloninger, was used (19, 20). This inventory consists of four temperament scales (novelty seeking, harm avoidance, reward dependence and persistence) and three character scales (self-directedness, cooperativeness and self-transcendence). Each question scores between 1 to 5; and the total score is the sum of all scores (20). The test-retest reliability, validity and internal consistency of the Persian version of the TCI were measured previously and found to be high. The Cronbach's alpha of this questionnaire is 0.76 . The Cronbach`s alpha of TCI scales mentioned previously were $0.75,0.72,0.87,0.9,0.76$, 0.66 and 0.86 for novelty seeking, harm avoidance, reward dependence, persistence, self-directedness, cooperativeness and self-transcendence, respectively (21). The SMS addiction test or short version of the selfperception of text-message dependency scale was designed by Igarashi and Motoyoshi in 2005 (22). It includes three subscales: perception of emotional responses, excessive use, and maintaining relationships (22). Each component consists of five items, which are scored using a Likert-type scale. The respondents were asked to rate each item on a 5-point Likert scale, from strongly agree (score 1) to strongly disagree (score 5), so the higher score means lower dependency to SMS. The reliability and validity of the Persian version of this test were evaluated and confirmed in earlier studies $(1,8)$.

\subsection{Statistical analysis}

The data were analysed using the IBM SPSS (version 11.5) statistical program. The statistical analysis was done using linear regression, Spearman's Rank-Order Correlation, independent-samples t-test, ANOVA, and KruskalWallis. In all the tests, the statistical significance level was considered as $\mathrm{p}<0.05$. After multiple Bonferronicorrected Mann-Whitney $U$ tests, a p value of 0.01 was taken as statistically significant. Linear regression test was also done to control the confounders (gender, educational level).

\subsection{Ethics}

All the procedures in this study were in conformity with the Declaration of Helsinki and were approved by the local Human Research Ethics Committee (IR.MUMS.REC.1394.120). After obtaining oral informed consent, the subjects were assured of anonymity and permission to leave at any stage of the study. No names are mentioned in the study.

\section{Results}

Two hundred and ninety-three medical students at various stages of their careers participated in this study. Two of the participants did not complete both questionnaires (response rate $=99 \%$ ). More than half of the participants were female $(53.7 \%)$. The mean age of the participants was $24.44 \pm 4.63$ years, with a range of $19-48$ years. Two hundred and seven students $(72.4 \%)$ were single. More than half of the participants $(51.1 \%)$ lived with their family, and the others resided in dormitories $(42.3 \%)$ or their own private house $(6.7 \%)$. More than $80 \%$ of the students reported that they had a mobile phone before the age of 20. Table 1 shows the evaluation of the correlation between the seven dimensions of the TCI and SAT. Note that SAT 1, 2 and 3 represent perception of emotional responses, excessive use and maintaining relationships respectively. As shown in Table 1, there was no significant correlation between reward dependence and persistence in three parts of the SAT questionnaire. Novelty seeking, cooperativeness, selfdirectedness and self-transcendence showed significant inverse correlations with the total SAT score ( $\mathrm{p}$-value equal to $0.003,<0.001,<0.001$ and 0.003 , respectively). Note that the correlation coefficients are very small.

The participants were divided according to their scores in each area of the TCI, with the top third labelled Group 1, the middle third labelled Group 2 and the lower third labelled Group 3. Table 2 presents the comparison of the total SAT scores of the groups. There was a significant difference between the mean of the total SAT in three state variables of novelty seeking, cooperativeness, self-directedness and self-transcendence ( $\mathrm{p}$-value equal to 0.02 , $<0.001,<0.001$ and 0.02 , respectively). With regard to the state variable Cooperativeness, a post hoc analysis of the ANOVA test showed that the total SAT score was significantly different between groups 3 and $1(p<0.001)$ and groups 3 and $2(\mathrm{p}=0.005)$. After applying a Kruskal-Wallis test, a Bonferroni correction was used to determine significant relations. The results of the Bonferroni-corrected Mann-Whitney tests indicated that there were significant differences in self-directedness between groups 1 and 3 ( $p=0.001)$ and groups 1 and $2(p<0.001)$. In both self-transcendence and novelty seeking, there were differences between groups 1 and 3 (p-value equal to 0.008 and 
0.004, respectively). The data on the participants' temperament and character were compared with Iranian normative data, derived from a study conducted in 2005 (21). Interestingly, the mean score in each area of the TCI differed significantly between the two datasets (Table 3 ).

Table 1. Correlation between dimensions of TCI and SAT in study population

\begin{tabular}{|c|c|c|c|c|c|}
\hline \multicolumn{2}{|l|}{ TCI scales } & SAT1* & SAT2* & SAT3* & Total SAT score \\
\hline \multirow[t]{3}{*}{ Novelty seeking } & The top third & $\mathrm{r}=-0.03, \mathrm{p}=0.8$ & $\mathrm{r}=0.01, \mathrm{p}=0.91$ & $\mathrm{r}=-0.3, \mathrm{p}=0.02$ & $\mathrm{r}=-0.15, \mathrm{p}=0.25$ \\
\hline & The lower third & $\mathrm{r}=0.1, \mathrm{p}=0.31$ & $\mathrm{r}=-0.21, \mathrm{p}=0.03$ & $\mathrm{r}=-0.07, \mathrm{p}=0.46$ & $\mathrm{r}=-0.09, \mathrm{p}=0.34$ \\
\hline & Total score & $\mathrm{r}=-0.14, \mathrm{p}=0.01$ & $\mathrm{r}=-0.2, \mathrm{p}=0.001$ & $\mathrm{r}=-0.1, \mathrm{p}=0.09$ & $\mathrm{r}=-0.17, \mathrm{p}=0.003$ \\
\hline \multirow[t]{3}{*}{ Harm avoidance } & The top third & $\mathrm{r}=0.11, \mathrm{p}=0.34$ & $\mathrm{r}=0.04, \mathrm{p}=0.67$ & $\mathrm{r}=-0.04, \mathrm{p}=0.73$ & $\mathrm{r}=0.08, \mathrm{p}=0.47$ \\
\hline & The lower third & $\mathrm{r}=-0.24, \mathrm{p}=0.01$ & $\mathrm{r}=-0.02, \mathrm{p}=0.79$ & $\mathrm{r}=-0.16, \mathrm{p}=0.08$ & $\mathrm{r}=-0.17, \mathrm{p}=0.06$ \\
\hline & Total score & $\mathrm{r}=-0.16, \mathrm{p}=0.006$ & $\mathrm{r}=-0.1, \mathrm{p}=0.09$ & $\mathrm{r}=-0.06, \mathrm{p}=0.3$ & $\mathrm{r}=-0.11, \mathrm{p}=0.053$ \\
\hline \multirow{3}{*}{$\begin{array}{l}\text { Reward } \\
\text { dependence }\end{array}$} & The top third & $\mathrm{r}=-0.04, \mathrm{p}=0.72$ & $\mathrm{r}=-0.01, \mathrm{p}=0.93$ & $\mathrm{r}=-0.07, \mathrm{p}=0.55$ & $\mathrm{r}=-0.02, \mathrm{p}=0.84$ \\
\hline & The lower third & $\mathrm{r}=0.01, \mathrm{p}=0.86$ & $\mathrm{r}=-0.06, \mathrm{p}=0.52$ & $\mathrm{r}=-0.02, \mathrm{p}=0.78$ & $\mathrm{r}=-0.01, \mathrm{p}=0.86$ \\
\hline & Total score & $\mathrm{r}=-0.03, \mathrm{p}=0.61$ & $\mathrm{r}=-0.05, \mathrm{p}=0.33$ & $\mathrm{r}=-0.08, \mathrm{p}=0.17$ & $\mathrm{r}=-0.05, \mathrm{p}=0.33$ \\
\hline \multirow[t]{3}{*}{ Persistence } & The top third & $\dagger$ & $\dagger$ & $\dagger$ & $\dagger$ \\
\hline & The lower third & $\mathrm{r}=-0.01, \mathrm{p}=0.84$ & $\mathrm{r}=-0.03, \mathrm{p}=0.74$ & $\mathrm{r}=-0.01, \mathrm{p}=0.89$ & $\mathrm{r}=-0.02, \mathrm{p}=0.77$ \\
\hline & Total score & $\mathrm{r}=0.06, \mathrm{p}=0.26$ & $\mathrm{r}=0.06, \mathrm{p}=0.25$ & $\mathrm{r}=0.06, \mathrm{p}=0.25$ & $\mathrm{r}=0.09, \mathrm{p}=0.1$ \\
\hline \multirow[t]{3}{*}{ Cooperativeness } & The top third & $\mathrm{r}=-0.01, \mathrm{p}=0.87$ & $\mathrm{r}=-0.08, \mathrm{p}=0.49$ & $\mathrm{r}=-0.01, \mathrm{p}=0.91$ & $\mathrm{r}=-0.06, \mathrm{p}=0.58$ \\
\hline & The lower third & $\mathrm{r}=-0.02, \mathrm{p}=0.81$ & $\mathrm{r}=-0.14, \mathrm{p}=0.13$ & $\mathrm{r}=0.05, \mathrm{p}=0.54$ & $\mathrm{r}=-0.02, \mathrm{p}=0.82$ \\
\hline & Total score & $\mathrm{r}=-0.21, \mathrm{p}<0.001$ & $\mathrm{r}=-0.22, \mathrm{p}<0.001$ & $\mathrm{r}=-0.2, \mathrm{p}<0.001$ & $\mathrm{r}=-0.24, \mathrm{p}<0.001$ \\
\hline \multirow[t]{3}{*}{ Self-directedness } & The top third & $\mathrm{r}=-0.15, \mathrm{p}=0.13$ & $\mathrm{r}=-0.05, \mathrm{p}=0.6$ & $\mathrm{r}=-0.14, \mathrm{p}=0.15$ & $\mathrm{r}=-0.11, \mathrm{p}=0.24$ \\
\hline & The lower third & $\mathrm{r}=-0.14, \mathrm{p}=0.14$ & $\mathrm{r}=-0.28, \mathrm{p}=0.003$ & $\mathrm{r}=-0.07, \mathrm{p}=0.43$ & $\mathrm{r}=-0.18, \mathrm{p}=0.05$ \\
\hline & Total score & $\mathrm{r}=-0.27, \mathrm{p}<0.001$ & $\mathrm{r}=-0.17, \mathrm{p}=0.003$ & $\mathrm{r}=-0.19, \mathrm{p}=0.001$ & $\mathrm{r}=-0.24, \mathrm{p}<0.001$ \\
\hline \multirow{3}{*}{$\begin{array}{l}\text { Self- } \\
\text { transcendence }\end{array}$} & The top third & $\mathrm{r}=0.01, \mathrm{p}=0.89$ & $\mathrm{r}=-0.05, \mathrm{p}=0.59$ & $\mathrm{r}=0.009, \mathrm{p}=0.93$ & $\mathrm{r}=-0.06, \mathrm{p}=0.52$ \\
\hline & The lower third & $\mathrm{r}=0.06, \mathrm{p}=0.51$ & $\mathrm{r}=-0.1, \mathrm{p}=0.29$ & $\mathrm{r}=-0.17, \mathrm{p}=0.07$ & $\mathrm{r}=-0.1, \mathrm{p}=0.26$ \\
\hline & Total score & $\mathrm{r}=-0.17, \mathrm{p}=0.004$ & $\mathrm{r}=-0.2, \mathrm{p}=0.001$ & $\mathrm{r}=-0.09, \mathrm{p}=0.09$ & $\mathrm{r}=-0.17, \mathrm{p}=0.003$ \\
\hline
\end{tabular}

$\dagger$ Correlation could not be tested because the total participants` score in this group was equal to 5. *SAT: SMS Addiction Test. Note that SAT 1, 2 and 3 represent perception of emotional responses, excessive use and maintaining relationships respectively

Table 2. Mean SAT score in the different scales of the TCI

\begin{tabular}{|c|c|c|c|}
\hline TCI scales & & SAT score $($ Mean \pm SD) & p-value \\
\hline \multirow{3}{*}{ Novelty seeking } & Group 1 & $47.36 \pm 12.34$ & \multirow[t]{3}{*}{$0.02 *$} \\
\hline & Group 2 & $49.21 \pm 12.67$ & \\
\hline & Group 3 & $51.57 \pm 9.58$ & \\
\hline \multirow[t]{3}{*}{ Harm avoidance } & Group 1 & $47.36 \pm 13.69$ & \multirow[t]{3}{*}{$0.16^{*}$} \\
\hline & Group 2 & $50.34 \pm 12.43$ & \\
\hline & Group 3 & $50.52 \pm 9.4$ & \\
\hline \multirow[t]{3}{*}{ Reward dependence } & Group 1 & $49.4 \pm 13.34$ & \multirow[t]{3}{*}{$0.51 * *$} \\
\hline & Group 2 & $48.78 \pm 10.68$ & \\
\hline & Group 3 & $50.6 \pm 11.52$ & \\
\hline \multirow[t]{3}{*}{ Persistence } & Group 1 & $52.66 \pm 11.77$ & \multirow[t]{3}{*}{$0.26^{* *}$} \\
\hline & Group 2 & $50.01 \pm 12.59$ & \\
\hline & Group 3 & $48.57 \pm 10.48$ & \\
\hline \multirow[t]{3}{*}{ Cooperativeness } & Group 1 & $44.81 \pm 12.74$ & \multirow[t]{3}{*}{$<0.001 * *$} \\
\hline & Group 2 & $50.62 \pm 9.3$ & \\
\hline & Group 3 & $52.05 \pm 11.87$ & \\
\hline \multirow[t]{3}{*}{ Self-directedness } & Group 1 & $47.37 \pm 13.78$ & \multirow[t]{3}{*}{$<0.001^{*}$} \\
\hline & Group 2 & $47.52 \pm 9.25$ & \\
\hline & Group 3 & $53.12 \pm 10.42$ & \\
\hline \multirow[t]{3}{*}{ Self-transcendence } & Group 1 & $47.87 \pm 14.26$ & \multirow[t]{3}{*}{$0.02 *$} \\
\hline & Group 2 & $48.55 \pm 11.13$ & \\
\hline & Group 3 & $52 \pm 9.36$ & \\
\hline
\end{tabular}

*Kruskal-Wallis test; **ANOVA 
Table 3. Comparison of dimensions of TCI (current study) vs. normal population (Kaviani Study)

\begin{tabular}{|l|l|l|l|l|}
\hline & Current Study & Kaviani Study & CI* & p-value** \\
\hline $\begin{array}{l}\text { Novelty seeking } \\
(\text { mean } \pm \text { SD) }\end{array}$ & $10.39 \pm 2.95$ & $8.45 \pm 3.67$ & $1.6 ; 2.28$ & $<0.001$ \\
\hline $\begin{array}{l}\text { Harm avoidance } \\
(\text { mean } \pm \text { SD) }\end{array}$ & $8.98 \pm 2.98$ & $7.5 \pm 4.3$ & $1.14 ; 1.83$ & $<0.001$ \\
\hline $\begin{array}{l}\text { Reward dependence } \\
(m e a n \pm \text { SD) }\end{array}$ & $8.08 \pm 2.04$ & $8.5 \pm 2.38$ & $-0.64 ;-0.17$ & 0.001 \\
\hline $\begin{array}{l}\text { Persistence } \\
(\text { mean } \pm \text { SD) }\end{array}$ & $2.69 \pm 1.42$ & $3.11 \pm 1.42$ & $-0.58 ;-0.25$ & $<0.001$ \\
\hline Cooperativeness $(m e a n \pm S D)$ & $12.9 \pm 3.29$ & $18.47 \pm 3.99$ & $-5.94 ;-5.18$ & $<0.001$ \\
\hline Self-directedness $(m e a n \pm S D)$ & $10.98 \pm 4.28$ & $15.08 \pm 5.05$ & $-4.58 ;-3.6$ & $<0.001$ \\
\hline Self-transcendence $(m e a n \pm S D)$ & $7.63 \pm 3.11$ & $9.96 \pm 3.1$ & $-2.68 ;-1.96$ & $<0.001$ \\
\hline
\end{tabular}

* Confidence Interval; ** Independent-samples t-test

Table 4 shows the result of linear regression. We put SAT as a dependent variable and all seven scales of TCI and demographics including age, gender and grade level as independent variables. We used the enter model for regression analysis. As the correlation coefficient of age with grade level was 0.8 , we removed age from the model. As we see in Table 4, three variables are statistically significant in the model (self-directedness, gender and grade level). Males have a higher SAT score. The mean of the total SAT score was $49.65 \pm 11.71$. After dividing the participants according to grade, the residents group had the highest mean SAT score. The median and interquartile range of the total SAT score in the basic science, externship, internship and residency groups were $50(45.25,55.5)$, $46(39,54), 46(40.5,55)$ and $57(51.75,63.25)$, respectively. The results of the Kruskal-Wallis test pointed to a significant difference in the total SAT scores according to the grade/level of the student $(p<0.001)$. The mean total SAT score between the two genders was also compared. The median score of male students was higher than that of females ( 51 vs. 49 ), but there was no significant relationship between the score in these two groups ( $p=0.06$, MannWhitney U test). Eighteen (6.3\%) students declared that they were smokers. The participants were divided into two groups, according to the median of the total SAT score: those with a total SAT score of more than 50 ( $\mathrm{n}=134$, $47.68 \%)$ and those with a total SAT score of less than $50(\mathrm{n}=147,52.32 \%)$. The results revealed no significant relationship between current smoking behaviour (smoking and non-smoking) and SMS usage (according to total SAT score $)(\mathrm{Phi}=0.016, \mathrm{p}=0.78)$.

Table 4. Linear regression for predicting the SAT score (enter model)

\begin{tabular}{|l|l|l|l|l|}
\hline \multirow{2}{*}{ Constant } & \multirow{2}{*}{ Standardized B } & \multicolumn{2}{|l|}{ Confidence Interval } & \multirow{2}{*}{ p-value } \\
\cline { 3 - 5 } & & Lower bound & Upper bound & \\
\hline Novelty seeking & -0.011 & -0.624 & 0.533 & 0.878 \\
\hline Harm avoidance & 0.029 & -0.411 & 0.644 & 0.664 \\
\hline Reward dependence & -0.052 & -1.011 & 0.404 & 0.398 \\
\hline Persistence & 0.103 & -0.12 & 1.815 & 0.086 \\
\hline Cooperativeness & -0.112 & -0.961 & 0.086 & 0.101 \\
\hline Self-directedness & $\mathbf{- 0 . 1 7 3}$ & -0.837 & -0.145 & $\mathbf{0 . 0 0 6}$ \\
\hline Self-transcendence & -0.063 & -0.722 & 0.24 & 0.325 \\
\hline Gender (Ref: male) & $\mathbf{- 0 . 1 2 3}$ & -5.604 & -0.2 & $\mathbf{0 . 0 3 5}$ \\
\hline Grade level & $\mathbf{0 . 1 8 4}$ & 0.678 & 3.28 & $\mathbf{0 . 0 0 3}$ \\
\hline
\end{tabular}

\section{Discussion}

Novelty seeking, cooperativeness, self-directedness and self-transcendence showed significant inverse correlation with total SAT score. There was significant difference between the mean of the total SAT in three state variables of novelty seeking, cooperativeness, self-directedness and self-transcendence. The residents' group had the highest mean SAT score among all the students. There was a significant difference in the total SAT scores according to the grade of the student $(\mathrm{p}<0.001)$.

In this study, the total SAT score of female students was lower than that of males. Although the gender differences in mobile phone addiction were discussed in previous studies, there is no agreement on this subject (13). The results 
of the current study were the same as two other studies conducted in Iran in 2011 and 2012, respectively (6). Both studies reported no significant difference between the SMS addiction of males and females, although the women had a slightly higher score than the men in one of the studies (3). On the other hand, in a study from Switzerland, the two gender patterns of mobile phone use in 17-27-year-old individuals were compared and it was shown that girls were more likely to use their mobile phone for texting and the dependency to mobile phones was also higher in girls (23). Also, some other studies found that the dependency to mobile phones and text messages are more severe in women in comparison with men (24-27). To explain these results, it seems necessary to note the different uses of mobile phones in males and females. According to some studies, women are more likely than men to use a mobile phone to maintain social relationships and express emotions, whereas men use it as an instrument to organise their business lives (i.e. arrange meetings, etc.) $(1,24)$. In other words, women more frequently use their mobile phone for emotional purposes such as satisfying the need for acceptance while men use their mobile phone for playing, taking pictures, and listening to music and this difference can be a reason for more dependency in girls $(13,28)$. Studies conducted in Finland and Japan found that girls were more inclined than boys to maintain relationships via text messages $(29,30)$. The Japanese study also found that girls were more likely than boys to expand their social networks via mobile phone text messages (30). Another study reported similar findings, with women significantly more inclined than men to communicate via mobile phone than in person (31). All the aforementioned studies included students aged 13-23. Along with all mentioned views about gender and phone dependence, the high SAT score in males in this study could be due to their use of phones in line with their work and handling or coordinating shifts and nocturnal care, although this justification is only applicable regarding interns and residents, who work night shifts.

In two different studies of medical students in India, about $90 \%$ and $70 \%$ of participants declared that they kept their mobile phone under their pillows or near their beds $(32,33)$. Another study indicated that $22.9 \%$ of Polish and $10.4 \%$ of Belarusian students had symptoms of mobile phone addiction (34). In the current study, nearly $50 \%$ of the participants had a median total SAT score of more than 50. This could show a sign of desire to exchange information in youths (especially in students). A review by Pérez in 2012 noted that the estimated prevalence ranges of mobile phone addiction varied from $0-38 \%$, depending on the scale used and the characteristics of the population studied (35). In a study conducted in Ethiopia in 2014, about $41 \%$ of medical students were high-volume SMS users (36). In another study conducted in Japan, most of the students were considered healthy, with regard to SMS dependency (18). It should be noted that this study involved nursery students and that most of the participants said that they had recently used their mobile phones (18). According to an SMS addiction test administered to Tunisian high-school students, $31.7 \%$ reported excessive use, 33.4\% reported emotional dependency on SMSs, and 18\% relied on SMSs to maintain relationships (37). For these three variables, figures of $53.3 \%, 52.3 \%$ and $16.8 \%$, respectively, were reported in a study of medical students in Bandar Abbas, Iran (8).

In the present study, the median and interquartile range of the total SAT scores in the residency group were higher than in other groups. Although this finding was not discussed in previous studies in this form, Geser mentioned that by students getting older, their dependency to mobile phones increases (23). On the other hand, Augner found that age is negatively correlated with problematic mobile phone use (38). The reason for higher use of phones in the current study could be due to non-problematic phone use, which is higher among residents with more responsibilities regarding their work and patients.

As noted earlier, in the present study, the total SAT score of the top third (Group 1) and lower third (Group 3) for the dimensions of novelty seeking, cooperativeness, self-directedness and self-transcendence was significantly different. A previous study also showed that the frequency of mobile phone text message communication was significantly associated with high novelty seeking (18). Some previous studies employed the NeuroticismExtraversion-Openness Personality Inventory-Revised test (NEO PI-R) to assess the relationship between SMS addiction and personality. Two studies reported a positive relationship between neuroticism and addiction to text messages $(3,39)$. Both of those studies consisted of high-school students. Using the NEO inventory, studies of college students also found a positive relationship between extroversion and SMS usage (40). A review revealed that low self-esteem was the most common personality trait associated with SMS addiction but that extraversion was also associated with excessive usage (35). It has been shown that low self-esteem can be linked to addictive behavior (41). The difference between SAT scores in the top third and lower third of Self-Directedness and SelfTranscendence dimensions could be explained by knowing that using mobile phones can help persons with low selfesteem to escape from aversive situations (24). This issue applied for all people with different socioeconomic or educational levels, with no exception, whether medical students or not. Also, extroversion can be defined as being 
sociable, needing to be accepted by others and a dislike for working alone (42) and it seems to be an important predictor of mobile phone addiction. Indeed an extrovert tries to find stimulation and requires novel sensations and experiences. Also, extroverts are more sociable and this makes them more susceptible to addiction. It was mentioned that low self-esteem, extroversion and neuroticism are linked to mobile phone addiction $(24,43)$. Totally, without considering SMS patterns, Vaidya found that medical students who stated that they would study surgery, emergency medicine or gynaecology in the future were higher on novelty seeking. The same study reported that the students who selected surgery had low scores for variable harm avoidance and reward dependence and that those who choose paediatrics had high scores for variable reward dependence (44). Kluger indicated that physicians in New Zealand were more cooperative than the community sample in this country (45). According to the long-term course of medicine and its content, it is not unexpected that most students who study medicine are really eager to this field and are also curious to know more about complex items. This may be attributed to the novelty seeking of medical students.

In the present study, the mean scores of each area of the TCI differed significantly from those reported by Kaviani, who presented Iranian normative data (20). The mean scores for novelty seeking and Harm Avoidance were higher in the current study compared to those reported by Kaviani, whereas the mean score for other variables were higher in Kaviani's study. As the current study was focused solely on medical students, the results were different from the general population mentioned in Kaviani 's study. It could be due to the age of the participants. In our study, all the participants were students with a mean age of about 25 years old, while in Kaviani's study about $60 \%$ of participants were older than 30. In Iran, medicine is one of the first selections of talented students studying in high schools. Medical students are involved in complex situations brought on by patients, difficult lessons and the long duration of studying, so they would differ from the general population in some areas of personality. The other point could be the mean age of participants. As the majority of text messages today are transferred via the Internet using social networks and various applications such as Telegram and Viber, the findings of the present study may point to a high level of Internet addiction, in addition to SMS addiction. These various applications also lead to high usage of SMS.

\section{Limitations}

Some limitations of the present study should be noted. The study would have benefited by comparing SMS usage among medical students from different fields (i.e. with different specialities). As noted previously, some studies found that there were differences between the characteristics of students in different specialities $(44,45)$. A lack of information regarding alcohol and substance use was another limitation of this study.

\section{Conclusions}

According to the results of this study, novelty seeking, cooperativeness, self-directedness and self-transcendence showed significant inverse correlation with total SAT; and the residents group had the highest mean SAT score. As this study focused solely on medical students (who are younger and often more advanced than the general population) it is not unexpected to find more novelty seeking in this group. Novelty seeking is expected to feature more in the first years of living in a new situation, and by adapting, (medical residents compare with students in the first years) novelty seeking decreases and the SAT shows higher scores. Although communication technology, such as SMS, has many positive effects on human lives today, it is a dual-edged sword, with dependency on such technology having adverse physical and psychological effects on health. It is recommended to investigate in this field in future studies. Recognizing people with this issue is important to take proper preventive strategies.

\section{Acknowledgments:}

This study was financially supported by the Vice Chancellery of Research, Mashhad University of Medical Sciences (Ref: 930914).

\section{Conflict of Interest:}

There is no conflict of interest to be declared.

\section{Authors' contributions:}

All authors contributed to this project and article equally. All authors read and approved the final manuscript.

\section{References:}

1) Hassanzadeh R, Rezaei A. Effect of sex, course and age on SMS addiction in students. Middle-East Journal of Scientific Research. 2011; 10(5): 619-25. 
2) Lopez-Fernandez O, Männikkö N, Kääriäinen M, Griffiths MD, Kuss DJ. Mobile gaming and problematic smartphone use: A comparative study between Belgium and Finland. Journal of behavioral addictions. 2018; 7(1): 88-99. doi: 10.1556/2006.6.2017.080. PMID: 29313732, PMCID: PMC6035026.

3) Beydokhti A, Hassanzadeh R, Mirzaian B. The relationship between five main factors of personality and addiction to SMS in high school students. Current Research Journal of Biological Sciences. 2012; 4(6): 685-9.

4) Hoffner CA, Lee S, Park SJ. "I miss my mobile phone!": Self-expansion via mobile phone and responses to phone loss. New Media \& Society. 2016; 18(11): 2452-68. doi: 10.1177/1461444815592665.

5) Lepp A, Barkley JE, Karpinski AC. The relationship between cell phone use, academic performance, anxiety, and satisfaction with life in college students. Computers in Human Behavior. 2014; 31: 343-50. doi: 10.1016/j.chb.2013.10.049.

6) Golmohammadian M, Yaseminejad P. Normalization, validity and reliability of Cell-phone Over-use Scale (COS) among university students. 2011.

7) Madell DE, Muncer SJ. Control over social interactions: an important reason for young people's use of the Internet and mobile phones for communication? Cyberpsychol behav. 2007; 10(1): 137-40. doi: 10.1089/cpb.2006.9980. PMID: 17305461.

8) Hesam AA, Safari Moradabadi A, Avazpoor N, Ghanbarnejad A. Investigating demographic variables associated with text messaging addiction among students of Medical Sciences in Hormozgan University During 2013. Journal of Applied Science and Agriculture. 2013.

9) Igarashi T, Motoyoshi T, Takai J, Yoshida T. No mobile, no life: Self-perception and text-message dependency among Japanese high school students. Computers in Human Behavior. 2008; 24(5): 2311-24. doi: 10.1016/j.chb.2007.12.001.

10) Zokaei M, Taj Mazinani A, Karimi A. SMS role in youth life. Journal of Sociological Studies of Youth. 2014; 5(14): 43-66.

11) Karadağ E, Tosuntaş ŞB, Erzen E, Duru P, Bostan N, Şahin BM, et al. Determinants of phubbing, which is the sum of many virtual addictions: A structural equation model. Journal of behavioral addictions. 2015; 4(2): 60-74. doi: 10.1556/2006.4.2015.005. PMID: 26014669, PMCID: PMC4500886.

12) Holohan M. Does your partner love his cellphone more than you? Take this survey 2015.

13) Suleiman Al-Barashdi H, Bouazza A, Jabur NH. Smartphone addiction among university undergraduates: a literature review. 2015.

14) Višnjić A, Veličković V, Sokolović D, Stanković M, Mijatović K, Stojanović M, et al. Relationship between the manner of mobile phone use and depression, anxiety, and stress in university students. International journal of environmental research and public health. 2018; 15(4): 697. doi: 10.3390/ijerph15040697. PMID: 29642471, PMCID: PMC5923739.

15) Javid M, Malik MA, Gujjar AA. Mobile Phone Culture and its Psychological Impacts on Students' Learning at the University Level. Language In India. 2011; 11(2).

16) Rodrigues A. The perceived impacts of smartphone use on the performance of senior managers in South African firms. Graduate School of Business, University of Cape Town Retrieved August. 2011; 31: 2014.

17) Jacobsen WC, Forste R. The wired generation: Academic and social outcomes of electronic media use among university students. Cyberpsychol Behav Soc Netw. 2011; 14(5): 275-80. doi: 10.1089/cyber.2010.0135. PMID: 20961220.

18) Lu X, Chen Z, Uji M, Nagata T, Katoh T, Kitamura T. Use of mobile phone text message and personality among Japanese university students. Psychology Behavioral Sci. 2013; 2: 192-5. doi: 10.11648/j.pbs.20130205.14.

19) Kaviani H, Hagshenas H. Preliminary study of adaptation and standardization temperament and character inventory (TCI). Adv Cogn Sci. 2000; 2(3-4): 18-24.

20) Kaviani H. Normative data on Temperament and Character Inventory (TCI): complimentary findings. Tehran University Medical Journal. 2009; 67(4).

21) Kaviani H, Pornaseh M. Standardization temperament and character inventory (TCI) on Iranian crowds. Tehran Uni Med J. 2005; 63(2): 89-98.

22) Igarashi T, Motoyoshi T, Takai J, Yoshida T, editors. The text messaging addiction scale: Factor structure, reliability, and validity. Sixth biennial conference of the Asian Association of Social Psychology, Wellington, New Zealand; 2005.

23) Geser H. Are girls (even) more addicted? Some gender patterns of cell phone usage. SSOAR. 2006.

24) Bianchi A, Phillips JG. Psychological predictors of problem mobile phone use. CyberPsychol Behav. 2005; 8(1): 39-51. doi: 10.1089/cpb.2005.8.39. PMID: 15738692. 
25) Chóliz M. Mobile-phone addiction in adolescence: the test of mobile phone dependence (TMD). Prog Health Sci. 2012; 2(1): 33-44.

26) Kawasaki N, Tanei S, Ogata F, Burapadaja S, Loetkham C, Nakamura T, et al. Survey on cellular phone usage on students in Thailand. Journal of Physiological Anthropology. 2006; 25(6): 377-82. doi: 10.2114/jpa2.25.377. PMID: 17213690 .

27) Leung L. Linking psychological attributes to addiction and improper use of the mobile phone among adolescents in Hong Kong. Journal of children and media. 2008; 2(2): 93-113. doi: 10.1080/17482790802078565.

28) Pawłowska B, Potembska E. Gender and severity of symptoms of mobile phone addiction in Polish gymnasium, secondary school and university students. Current Problems of Psychiatry. 2011; 12(4).

29) Wilska TA. Mobile phone use as part of young people's consumption styles. Journal of consumer policy. 2003; 26(4): 441-63. doi: 10.1023/A:1026331016172.

30) Igarashi T, Takai J, Yoshida T. Gender differences in social network development via mobile phone text messages: A longitudinal study. Journal of Social and Personal Relationships. 2005; 22(5): 691-713. doi: 10.1177/0265407505056492.

31) Pawlowska B, Potembska E. Gender and severity of symptoms of mobile phone addiction in Polish gymnasium, secondary school and university students. Current Problems of Psychiatry. 2011; 12(4): 433-8.

32) Arumugam B, Sachi S, Nagalingam S. A Descriptive Study On Behavior Associated With Mobile Phone Usage And Its Effect On Health Among Medical Students In Chennai. Journal of Evolution of Medical and Dental Sciences. 2014; 3(7): 1590-95. doi: 10.14260/jemds/2014/2029.

33) Singh B, Gupta R, Garg R. Mobile Phones; A Boon or Bane for Mankind?-Behavior of Medical Students. International Journal of Innovative Research and Development. 2013; 2(4): 196-205.

34) Krajewska-Kułak E, Kułak W, Stryzhak A, Szpakow A, Prokopowicz W, Marcinkowski J. Problematic mobile phone using among the Polish and Belarusian University students, a comparative study. Prog Health Sci. 2012; 2(1): 45-50.

35) Eduardo PP, Teresa M, Monje R, María J, Sanchez R, León D. Mobile Phone Abuse Or Addiction. A Review Of The Literature. Adicciones. 2012; 24(2).

36) Kumar SS. Mobile phone and adolescents-addiction a mindful check in! International Journal of Advanced Nursing Studies. 2014; 3(1): 42-6.

37) Halayem S, Nouira O, Bourgou S, Bouden A, Othman S, Halayem M. The mobile: a new addiction upon adolescents. Tunis Med. 2010; 88(8): 593-6. PMID: 20711967.

38) Augner C, Hacker GW. Associations between problematic mobile phone use and psychological parameters in young adults. International journal of public health. 2012; 57(2): 437-41. doi: 10.1007/s00038-011-0234z. PMID: 21290162.

39) Maron BA, Fein S, Maron BJ, Hillel AT, El Baghdadi MM, Rodenhauser P, editors. Ability of prospective assessment of personality profiles to predict the practice specialty of medical students. Baylor University Medical Center Proceedings. 2007.

40) Zhaoyun CSCSH, Qian L. The Research on Relation Between Short Message Service and Personality Characteristic for College Students. Psychology Exploration. 2005; 3.

41) Marlatt GA, Baer JS, Donovan DM, Kivlahan DR. Addictive behaviors: Etiology and treatment. Annual review of Psychology. 1988; 39(1): 223-52. doi: 10.1146/annurev.ps.39.020188.001255. PMID: 3278676.

42) Eysenck HJ. Dimensions of personality: 16, 5 or 3? Criteria for a taxonomic paradigm. Personality and Individual Differences. 1991; 12(8): 773-90.

43) Ezoe S, Toda M, Yoshimura K, Naritomi A, Den R, Morimoto K. Relationships of personality and lifestyle with mobile phone dependence among female nursing students. Social Behavior and Personality: an international journal. 2009; 37(2): 231-8. doi: 10.2224/sbp.2009.37.2.231.

44) Vaidya NA, Sierles FS, Raida MD, Fakhoury FJ, Przybeck TR, Cloninger CR. Relationship between specialty choice and medical student temperament and character assessed with Cloninger Inventory. Teaching and learning in medicine. 2004; 16(2): 150-6. doi: 10.1207/s15328015tlm1602_6. PMID: 15294460 .

45) Kluger M, Laidlaw T, Kruger N, Harrison M. Personality traits of anaesthetists and physicians: an evaluation using the Cloninger Temperament and Character Inventory (TCI - 125). Anaesthesia. 1999; 54(10): 926-35. doi: 10.1046/j.1365-2044.1999.01112.x. PMID: 10540055. 